\title{
Políticas públicas de lazer para a juventude pobre.
}

Bruno Gawryszewski*

Resumo: Este trabalho se propõe a fazer uma resenha do livro "Esporte e juventude pobre: as políticas públicas de lazer na Vila Olímpica da Maré" de autoria de Marcelo Paula de Melo. O referido autor se propõe a discutir o processo de concepção e implementação do projeto "Vila Olímpica da Maré", a partir de um referencial teórico centrado no pensador italiano Antonio Gramsci.

Palavras-chave: Políticas públicas. Atividades de lazer. Adolescente.

\section{INTRODUÇÃO}

Cuidar das "nossas crianças", definitivamente, está na ordem do dia. Temerosos por nossa juventude que teria por missão fazer do Brasil o país do futuro, fantasmas como a violência urbana, a delinqüência, o uso indiscriminado de drogas e o desemprego são considerados verdadeiras chagas que devem ser combatidas a qualquer preço.

Os ditos "projetos sociais" estão em voga nos mais diversos campos do país: eles são mencionados em noticiários, campanhas eleitorais e até nas altas rodas de "pessoas muito importantes" da sociedade. Uma onda de altruísmo parece tomar conta de nossos corações. Todos querem se mobilizar para salvar a juventude do "mau caminho".

Através dos "projetos sociais", o esporte, como um dos maiores fenômenos culturais de nosso tempo, assume uma dimensão

* Mestrando do Programa de Pós-Graduação em Educação pela Universidade Federal do Rio de Janeiro e Pesquisador do Grupo de Estudos em Trabalho, Educação Física e Materialismo Histórico pela Universidade Federal de Juiz de Fora. E-mail: brunog81@yahoo.com.br

Movimento, Porto Alegre, v.12, n. 03, p. 265-278, setembro/dezembro de 2006. 
socializante de promoção da cidadania àqueles que se encontram abandonados pelo poder público. Implementados através de parcerias entre o Estado e organismos da/na sociedade civil, os "projetos sociais" ampliam o conceito de Educação, redefinindo papéis atribuídos aos atores sociais no contexto de consolidação do projeto neoliberal no Brasil.

O livro "Esporte e Juventude Pobre: as politicas públicas de lazer na Vila Olímpica da Maré”, publicado pela editora Autores Associados, no ano de 2005, de autoria de Marcelo Paula de Melo se propõe a discutir o processo de idealização, concepção e implementação do projeto "Vila Olímpica da Maré". Utilizando-se de uma matriz teórica centrada em Antonio Gramsci, o autor desvela o referido projeto através de análises de documentos e entrevistas semi-estruturadas com os principais participantes do projeto.

\section{O ESTADO E A POLÍTICA NEOLIBERAL À LUZ DE GRAMSCI}

Melo situa o país na atual conjuntura política, tendo clareza do retorno a antigos preceitos do liberalismo clássico vestidos sob uma nova roupagem. Buscando ser a resposta burguesa para se contrapor ao projeto socialista e ao keynesianismo da Europa Ocidental, o neoliberalismo denuncia a intervenção do Estado na dinâmica social, interferindo em demasia nos rumos do mercado. Porém, o autor se apóia em Atílio Boron para afirmar de que a tese do Estado Mínimo é falaciosa, pois este teria se refuncionalizado através das privatizações, liberalizações dos mercados internos e desregulamentações que alteraram a dinâmica do sistema financeiro (BORON, 2001).

Contudo, a implementação de um programa mais rígido seguindo as recomendações formuladas por cânones como Hayek, Friedman e Popper se mostraram desastrosas, na medida em que os problemas sociais se agudizaram enormemente, especialmente

Movimento, Porto Alegre, v.12, n. 03, p. 265-278, setembro/dezembro de 2006. 
nos países periféricos do capitalismo. Assim, organismos multilaterais como o FMI e o Banco Mundial, sem sair do paradigma da economia de mercado, sustentam a idéia de planos de "alívio à pobreza" e "desenvolvimento sustentável". Então, tais organismos passam a ensaiar o incremento de sua atuação no intuito de desempenhar um papel de mediador/parceiro das relações entre Estado e sociedade civil, como se explicita no documento do Banco Mundial por Garrison (2000) "Do Confronto à Colaboração".

Assim como acima se mencionou a refuncionalização do papel do Estado, Melo sustenta que também houve uma refuncionalização dos direitos sociais, através da ideologia da chamada Terceira Via. A antiga noção de direitos sociais não caberia mais numa sociedade de risco, logo, caberia ao indivíduo se adaptar a esta nova etapa, utilizando-se dos serviços prestados à população, uma clara metamorfose da outrora idéia de universalização de direitos e igualdade de acesso e permanência a eles.

$\mathrm{O}$ autor evidencia que o ingresso definitivo do Brasil no reforço dos laços entre o Estado e a sociedade civil se deu em 1994, com a eleição para Presidente, do então Ministro da Fazenda, Fernando Henrique Cardoso. Vencendo no primeiro turno, seu nome foi elevado como aquele capaz de sintonizar o país na economia globalizada e na divisão internacional do trabalho, através da promoção de "reformas". Seu primeiro mandato se dedicou a algumas frentes principais como a valorização fictícia do Real frente ao dólar, a privatização de diversas empresas estatais, os empréstimos vultuosos que condicionaram o pagamento de juros estratosféricos para o país e a cortes no orçamento público. Porém, como forma de dar organicidade à implementação do projeto neoliberal, foi criado o Ministério da Administração e Reforma de Estado (MARE) com o objetivo de promover uma ampla reforma da aparelhagem estatal. Segundo Pereira e Grau (1999), titular do MARE, era preciso modernizar a administração pública brasileira tornando-a uma administração gerencial e não burocrática, que

Movimento, Porto Alegre, v.12, n. 03, p. 265-278, setembro/dezembro de 2006. 
segundo ele não atenderia aos desafios postos pela globalização. Assim, o Estado passou a ser "demonizado", ao mesmo tempo em que se clamava pela chamada descentralização administrava. Nessa onda, os organismos na sociedade civil surgiram como a solução modernizadora no que tange à implementação das políticas sociais.

Marcelo Melo debate o conceito de Estado e sociedade civil a partir do referencial teórico de Gramsci. Este debate resulta em considerável importância no momento de difusão indiscriminada do termo "sociedade civil". Entretanto, o mais fundamental é que a análise realizada dos conceitos referidos traz elementos concretos para a reflexão sobre a Vila Olímpica da Maré.

Dialogando com as análises gramscianas de Carlos Nelson Coutinho (1996, 2000) e Giovanni Semeraro (2001), Melo recupera a noção de que a sociedade civil para Gramsci, é um momento do Estado "ampliado". Essa concepção ampliada de Estado não considera apenas que existam aparelhos repressivos e ideológicos atuando em nome do Estado, mas também constituídos de aparelhos privados de hegemonia que se localizam na sociedade civil.

A análise da trajetória da sociedade civil brasileira, a partir dos anos 1970, oferece decisivas contribuições para entender sua conformação no século XXI. Entendendo o Brasil como uma sociedade de tipo "ocidental", diversos movimentos sociais surgem ao final da ditadura militar (Comunidades Eclesiais de Bases (CEBs), clubes de mães, novos partidos políticos, sindicatos, diversos movimentos sociais, associações de bairros) na luta pela afirmação de direitos universais e pela restauração da democracia. A apropriação do conceito de sociedade civil foi considerável para o recrudescimento da participação popular, segundo o entendimento de Doimo (1995).

Contudo, Melo critica a autora supracitada por não apontar que a leitura gramsciana da sociedade civil se deu em aversão ao Estado, tido como a máquina repressora. Assim, formulou-se a

Movimento, Porto Alegre, v.12, n. 03, p. 265-278, setembro/dezembro de 2006. 
imagem de que o Estado era o lugar do autoritarismo, da burocracia e da repressão, enquanto a sociedade civil seria o reino da liberdade, onde o jogo democrático vigorava sem percalços.

Nesse contexto, entra em cena um novo tipo de organismo na sociedade civil, as Organizações Não-Governamentais (ONGs). Surgidas inicialmente para atuar em pautas políticas nas quais os partidos não davam conta. Sob uma forte marca antiestatal, as ONGs se apresentam como responsáveis em preencher lacunas deixadas pelo "capitalismo selvagem". Com isso, Melo acerta ao interpretar as ONGs como humanizadoras do capitalismo.

Ao utilizar diversas citações do maior ícone das ONGs nos anos 1990, Herbert de Souza, o autor encadeia a idéia de que o embrião do chamado "Terceiro Setor" surge já no mandato de Fernando Collor, antecipando a tendência da defesa do "público não-estatal”, presente na Reforma de Estado realizada em 1998, já no governo de Fernando Henrique Cardoso.

O decisivo ponto de inflexão na atuação das ONGs ocorre no início dos anos 1990. Outrora financiado para atuarem em apoio aos movimentos sociais, as organizações passam a ser protagonistas na implementação de políticas, sejam públicas ou privadas. O autor destaca que o Programa Comunidade Solidária teve um papel fundamental na aproximação definitiva entre o Estado e as ONGs até à culminação da promulgação da Lei 9790/99 que cria a figura jurídica de Organizações da Sociedade Civil de Interesse Público (OSCIPs).

A criação do espectro "terceiro setor" emerge uma súbita onda de solidariedade, onde o termo "responsabilidade social" torna-se mais um clichê repetido constantemente. "Empresas cidadãs" se prontificam a ajudar o próximo, mas passam a se articular em organismo com o objetivo de obter incentivos fiscais empreender suas "cruzadas solidárias". No entender de Melo, a proposta pedagógica nesse movimento não pode ser minimizada, tendo em vista que, as empresas atentas à estratégia para o consenso, se

Movimento, Porto Alegre, v.12, n. 03, p. 265-278, setembro/dezembro de 2006. 
colocando como os novos mecenas. Fica evidente a proximidade de laços entre o projeto neoliberal e a ascensão de tais políticas.

\section{3 "NAS FAVELAS, NO SENADO..."}

Marcelo Melo se dedica no capítulo seguinte à discussão sobre as políticas públicas de esporte no Brasil. Para realizá-la, o autor chama a atenção para as relações de simbiose que os termos Educação Física e Esporte vem adquirindo nas últimas décadas, apesar de serem constituírem epistemologicamente de maneira diferenciada. Apesar de diferentes atribuições que podem ser dadas ao esporte, é notório que o esporte de alto rendimento atrai mais os olhares da sociedade.

A partir dos anos 1980, o direito ao esporte começa a fazer parte, ainda que timidamente, das reivindicações populares. Porém, sua implementação ainda é rodeada de práticas clientelistas e da profissionalização esportiva dos jovens envolvidos nas políticas. O grande mote para a legitimação das políticas públicas de esporte tem sido o da promoção da cidadania e da inclusão social, como mecanismos controladores da inquietude juvenil. Ao esporte cabe salvar os adolescentes do envolvimento com o uso ou o tráfico de drogas. O termo cidadania tornou-se auto-explicativo e possibilitar o acesso às práticas esportivas para a juventude pobre, significa conter um criminoso em potencial.

A partir da nova configuração da sociedade civil nos anos 1980, a afirmação do "Terceiro Setor" começa a ganhar materialidade através de algumas iniciativas. A mais famosa e antiga delas é a construção da Vila Olímpica da Mangueira em 1987, financiada por uma mega-empresa multinacional. Diversos atletas e artistas criaram seus "institutos da bondade" para vincular sua imagem a esse novo filão.

$\mathrm{O}$ autor se dedica a uma retrospectiva sobre a formação do complexo de favelas da Maré, que abriga dezesseis "Comunidades" e possui uma população de mais de 130.000 habitantes. O autor

Movimento, Porto Alegre, v.12, n. 03, p. 265-278, setembro/dezembro de 2006. 
destaca que o processo de relação tensa entre Estado e favela remonta fins do século XIX com a conhecida "reforma do Bota Abaixo" promovida pela gestão de Pereira Passos, passando pela expressiva remoção de moradores na década de 60 e à intervenção "pedagógica" através do acordo MEC-USAID que, dentre outras proposições, divulgava o que chamavam de Metodologia de Desenvolvimento Comunitário como forma de "superação" dos problemas dos bairros pobres e favelas, conforme o entendimento de Valla (1986).

A partir dos anos 1970, os moradores de favelas passam a se organizar politicamente através das Associações de Moradores. Assim, a perspectiva governamental de intervenção remocionista dá lugar aos planos de urbanização e integração das favelas à cidade. A favela da Maré, então era conhecida por suas numerosas palafitas construídas sobre o "lodo" da Baía de Guanabara, recebeu um vultuoso investimento no fim do governo do General João Figueiredo, o Projeto Rio, que visava o aterramento de parte da Baía de Guanabara, a regularização da propriedade dos terrenos, a instalação de rede de esgotos e a conseqüente transferência de todos os moradores para esta área urbanizada.

Um significativo impulso à pesquisa do referido autor foi a criação da União das Associações de Moradores da Maré (UNIMAR), em 1995. Sua criação foi crucial, pois os moradores puderam construir uma plataforma de reivindicações para a Maré como um todo, não importando a comunidade pela qual pertencesse.

No último capítulo, o pesquisador nos oferece sua principal contribuição, procurando investigar a idealização e conformação do projeto da Vila Olímpica da Maré à luz de uma perspectiva de análise gramsciana, a fim de compreender, a partir de uma experiência concreta, as relações imbricadas entre Estado e sociedade civil a partir dos anos 1990. O autor divide a trajetória da Vila Olímpica a partir criação da UNIMAR em 1995, passando pela eleição municipal de Luiz Paulo Conde (1997-2000) e a de César Maia (2001-2004).

Movimento, Porto Alegre, v.12, n. 03, p. 265-278, setembro/dezembro de 2006. 
A idéia da construção de um centro esportivo na favela da Maré surgiu em 1995, pouco depois da formação da UNIMAR. A primeira providência da associação foi a de abrir canais de interlocução com as esferas governamentais, o que foi conseguido com maior êxito com a Prefeitura, então administrada por César Maia. Contudo, os esperados avanços não ocorreram e os diretores da UNIMAR se dispersaram. Já no ano seguinte (1996), a Prefeitura retoma os debates para a implementação da Vila Olímpica junto à ONG Viva Rio e a UNIMAR é incorporada às discussões. Vale ressaltar a importância que o autor dispensa à participação do Viva Rio, uma ONG conhecida por sua íntima relação com os principais meios de comunicação do Rio de Janeiro e alta transitoriedade dentro dos órgãos públicos.

Com a visibilidade conseguida por conta da ligação com a "mega ONG", dissemina-se pelos meios de comunicação a necessidade da construção de uma Vila Olímpica, mais uma vez sob o ideário da redenção social. Seguindo o receituário da chamada modernização administrativa, desde o início o modelo de gestão pensado pela Prefeitura, o Viva Rio e a UNIMAR foi o de criação de uma ONG, conferindo a implementação de uma política pública para organismos na sociedade civil.

O ano de 1997 foi marcado pela aproximação do projeto com a COPPE/UFRJ, através dos Projetos de Centro/Redes de Excelência, o CENTEX. Situando o papel que a COPPE desempenha dentro da UFRJ, Melo não poupa críticas ao seu caráter de autonomia universitária, melhor definido como autofinanciamento, se baseando nos moldes propostos pelos maiores organismos internacionais de descompromisso do Estado com as universidades públicas de captação de verbas a partir de convênios com empresas públicas e privadas.

O trabalho proposto pelo CENTEX se assemelha a uma prestação de serviços de "solução de problemas e desenvolvimento de metodologias", assim como qualquer empresa privada se

Movimento, Porto Alegre, v.12, n. 03, p. 265-278, setembro/dezembro de 2006. 
oferece no mercado. A diferença é que o CENTEX vem revestido sob uma pura aura da universidade pública. Sua proposta consiste em disseminar parcerias - diferente de políticas públicas, como bem situa o autor - que atinjam níveis de excelência. Desde a sua concepção, o projeto coloca a necessidade de parcerias estratégicas para seu funcionamento, tanto no aporte financeiro, quanto na gestão de funcionamento. Nessa parceria, o papel do Estado jamais é descartado, sobretudo no que diz respeito ao financiamento inicial do empreendimento.

Nesse processo, é levada a cabo a proposta da criação de uma ONG para administrar sem fins lucrativos a Vila Olímpica, a UEVOM. A criação da ONG estava vinculada à idéia da "autonomia financeira", ou seja, que após o aporte inicial de recursos pela Prefeitura, a Vila Olímpica buscasse ser auto-sustentável através das parcerias sugeridas pela CENTEX. A UEVOM começou a operar em maio de 1999, composta por membros da Associação de Moradores, do Viva Rio e da Prefeitura.

O convênio entre a Prefeitura e a UEVOM é então assinado no dia 15 de dezembro de 1999. Imediatamente, a UEVOM começa sua caça aos financiadores e parceiros. Com a Petrobrás foram estabelecidos contatos assim que o projeto começou a funcionar efetivamente. Outra modalidade proposta era que cada modalidade esportiva contasse com um Atleta Lider, um esportista que, fazendo uso de sua notoriedade, captasse recursos para a Vila Olímpica.

Analisando os documentos dessas propostas, o autor ratifica a perspectiva de profissionalização esportiva dos jovens, citando casos como os acordos propostos com o Instituto Beneficente Romário de Souza Farias e o Clube de Regatas Flamengo, especialmente pela possibilidade de angariar recursos para o projeto. Melo critica, além da perspectiva salvacionista do esporte, a mercantilização das relações sociais e educativas, celebrando a lógica meritocrática e individualista de resolução dos problemas (MELO, 2005).

Movimento, Porto Alegre, v.12, n. 03, p. 265-278, setembro/dezembro de 2006. 
Para dar início às atividades da Vila Olímpica em fevereiro de 2000, o Viva Rio é contratado para contratar professores para as atividades oferecidas. No início do projeto, as aulas eram ministradas por pessoas da própria Maré que já tinham alguma inserção esportiva e legitimidade dentro de suas comunidades. Mas como o projeto do CENTEX previa, a UEVOM recorreu a recrutar professores e estagiários de Educação Física, o que acabou ocorrendo majoritariamente de pessoas oriundas da UFRJ.

A grande parceria obtida pela UEVOM ocorreu em junho de 2000, com a assinatura do contrato entre esta e a Petrobrás. Destarte, a empresa leva adiante a consolidação da política de "responsabilidade social corporativa". A empresa não tarda muito a explorar sua "solidariedade" nas campanhas publicitárias e nas premiações de empresa socialmente responsável.

No final de outubro de 2000, após as eleições municipais, o então Prefeito Luiz Paulo Conde é derrotado por César Maia. Imediatamente, a Presidência da UEVOM lhe envia uma carta de felicitação oferecendo-se como parceiro para o mandato do futuro prefeito.

Para o novo grupo à frente da Prefeitura, a manutenção da Vila Olímpica era estratégica, já que se configurava na única em forma de centro esportivo da Prefeitura em favelas cariocas, servindo este de molde para a construção de outras Vilas posteriormente. Algumas das diretrizes que norteiam a nova gestão exalam a mesmice de sempre: políticas de promoção do esporte para evitar "desvios sociais" e que, em médio prazo, possam inferir em melhora de indicadores sociais como repetência e evasão escolar, delinqüência infanto-juvenil, prostituição, consumo e tráfico de drogas, segundo documentos e pronunciamentos da Prefeitura Municipal do Rio de Janeiro.

Atento à atuação da Prefeitura, Melo aponta que, gradualmente, esta vai assumindo cada vez mais o controle do funcionamento da Vila Olímpica, inserindo-a como parte da política pública do município. A Vila Olímpica estabelece convênio com a Se-

Movimento, Porto Alegre, v.12, n. 03, p. 265-278, setembro/dezembro de 2006. 
cretaria de Educação para que algumas escolas levassem seus alunos a utilizarem as dependências da Vila, não ficando claro quando se tratava de aulas de Educação Física ou de práticas esportivas. Tais aulas careciam de maior consistência e planejamento já que as turmas não tinham professores fixos. Mas, conforme demonstra o autor, o importante era mostrar que a Vila sempre estivesse lotada de alunos, para justificar os investimentos feitos pela Petrobrás e a Prefeitura.

Um fator levantado pelo autor é o porquê da Vila Olímpica ter demorado tanto a atrair um número significativo de alunos, mesmo se tratando de uma área tão carente de investimentos e bem-estar social. Melo sugere algumas possibilidades como a maneira como foi formada a ONG da Vila Olímpica, a mudança na natureza da atuação dos Agentes Comunitários e a suspeita de que a VOM seria apenas mais um projeto eleitoreiro.

Outra característica que marcou na implementação da Vila Olímpica da Maré, como outras, foi o recrutamento de lideranças comunitárias para a direção. Seja para conferir legitimidade interna aos projetos, seja para viabilizá-los, o fato constatado pelo autor é que esses líderes estabeleceram práticas clientelistas no que tange à obtenção de empregos no projeto. Esses líderes parecem também exercer um papel de articuladores de consenso, na medida em que, mesmo que os trabalhadores estivessem sob precárias condições de seguridade, os ânimos são arrefecidos pela figura do imponente líder. Vale reforçar que nenhuma das Vilas Olímpicas no Rio de Janeiro apresentavam direitos trabalhistas regidos pela CLT, muito menos estabilidade de cargo ou concursos públicos.

Uma face constatada por Marcelo Melo foi a política de promoção do voluntariado como forma de sustentar e viabilizar a continuidade do projeto. Trata-se da construção de uma idéia perversa de obrigar a um "agradecimento" pela dádiva concedida por Deus e pela Prefeitura.

Movimento, Porto Alegre, v.12, n. 03, p. 265-278, setembro/dezembro de 2006. 
Já em 2003, atormentada por algumas dificuldades financeiras, inclusive com suspeitas de "convênios" do espaço da Vila com escolas privadas da região, os funcionários administrativos ficaram aproximadamente 3 meses sem receber seus ordenados. $\mathrm{O}$ encaminhamento dado pela direção foi a ameaça de que, caso as atividades fossem definitivamente paralisadas por algum tipo de greve ou rebelião, a própria continuidade do projeto estaria em risco. Ficou evidente a dimensão educativa conformadora de desestimular qualquer processo reivindicativo dos trabalhadores.

Então, por fim, a Vila Olímpica fica sem presidente em dezembro de 2003, depois de sua renúncia alegando problemas de saúde. A Vila Olímpica retomou suas atividades apenas em julho de 2004.

\section{CONSIDERAÇÕES FINAIS}

Pela pesquisa conduzida pelo autor, ficou constatado a concretização de um novo modelo de políticas públicas, infringindo novas relações entre o Estado e os organismos na sociedade civil. Marcelo Melo tem o mérito de expor a materialidade concreta dos preceitos neoliberais traçados pela burguesia, ávida em explorar novas esferas de investimento, utilizando-se de novas estratégias de inserção no mercado, no caso, o emergente mercado social e a permanente função do poder público de utilizar a máquina do Estado para fins particulares.

Reivindicando o acesso e a importância da vivência que o esporte possibilita aos jovens, o autor sustenta a necessidade da promoção do esporte enquanto um direito universal, porém sem perder de vista que o panorama constatado só há de ser definitivamente superado com a derrocada do sistema capitalista. 
Public politic of leisure for poor youth Abstract: This work if considers to present the book "Sport and poor youth: the public politics of leisure in Vila Olímpica of Maré", of authorship of Marcelo Paula de Melo. The related author if considers to argue the process of conception and implementation of the project "Vila Olímpica of Maré", from a theoretical referencial centered in the Italian thinker Antonio Gramsci.

Keywords: Public policies. Leisure activities. Adolescent.

Políticas públicas del ocio para la juventud pobre

Resumen: Este trabajo espera presentar el libro "Deporte y juventud pobre: las políticas públicas del ocio en la Vila Olímpica de Maré", de autoría del profesor Marcelo Paula de Melo. El autor relacionado si considera a discutir el proceso del concepto y la puesta en práctica del proyecto "Vila Olímpica de Maré", de un referencial teórico centrada en el pensador italiano Antonio Gramsci.

Palabras clave: Políticas públicas. Actividades recreativas. Adolescente.

\section{REFERÊNCIAS}

BORON, Atilio. Os "novos Leviatãs" e a pólis democrática: neoliberalismo decomposição estatal e a decadência da democracia na América Latina. In SADER, Emir; GENTILI, Pablo. (org.) Pós-neoliberalismo II: que Estado para que democracia? 3. ed. Petrópolis: Vozes, 2001. p. 7-67.

COUTINHO, Carlos Nelson. Contra Corrente: ensaios sobre democracia e socialismo. São Paulo; Cortez, 2000.

COUTINHO, Carlos Nelson. Marxismo e Política: a dualidade de poderes e outros ensaios. 2. ed. São Paulo: Cortez; 1996.

DOIMO, Ana Maria. A Vez e a Voz do popular: movimentos sociais e participação política no Brasil pós-70. Rio de Janeiro: ANPOCS/Relume Dumará, 1995.

Movimento, Porto Alegre, v.12, n. 03, p. 265-278, setembro/dezembro de 2006. 
GARRISON, John W. Do Confronto à Colaboração: Relações entre Sociedade Civil, o Governo e o Banco Mundial. Brasília: Banco Mundial, 2000.

MELO, Marcelo Paula. Esporte e juventude pobre: as políticas públicas de lazer na Vila Olímpica da Maré. Campinas: Autores Associados, 2005.

PEREIRA, Luiz Carlos Bresser; GRAU, Nurria Cunnil. Entre o Estado e o mercado: o público não-estatal. In:___. (Org.). O público não estatal na reforma do Estado. São Paulo: FGV; 1999. p. 15-48.

SEMERARO, Giovanni. Gramsci e a sociedade civil: cultura e educação para a democracia. 2. ed. Petrópolis, RJ: Vozes; 2001.

VALLA, Victor Vincent. (org.) Educação e Favela: políticas para as favelas do Rio de Janeiro. 1940-1985. Petrópolis, RJ: Vozes, 1986. 